\title{
What We Know about Numbers and Propositions and How We Know It
}

\author{
Scott Soames*
}

Received: 30 December 2019 / Accepted: 24 January 2020

Abstract: The paper sketches and defends two instances of the strategy Let $N$ 's be whatever they have to be to explain our knowledge of them - one in which N's are natural numbers and one in which N's are propositions. The former, which makes heavy use of Hume's principle and plural quantification, grounds our initial knowledge of number in (a) our identification of objects as falling under various types, (b) our ability to count (i.e. to pair memorized numerals with individuated objects of one's attention), (c) our (initially perceptual) recognition of plural properties (e.g. being three in number), and (d) our predication of those properties of pluralities that possess them (even though no individuals in the pluralities do). Given this foundation, one can use Fregean techniques to non-paradoxically generate more extensive arithmetical knowledge. The second instance of my metaphysics-in-the-service-of-epistemology identifies propositions (i.e. semantic contents of some sentences, objects of the attitudes, and bearers of truth, falsity, necessity, contingency, and apriority) with certain kinds of purely representational cognitive acts, operations, or states. In addition to providing natural solutions to traditionally unaddressed epistemic problems involving linguistic cognition and language use, I argue that this metaphysical conception of propositions expands the solution spaces of many of the most recalcitrant and

* University of Southern California

- University of Southern California School of Philosophy, 3709 Trousdale Parkway, MHP 113 (223 Stonier Hall), Los Angeles, CA 90089, U.S.A.

$\bowtie$ soames@usc.edu

() The Author. Journal compilation (C) The Editorial Board, Organon F.

This article is distributed under the terms of the Creative Commons Attribution-NonCommercial 4.0 International Public License (CC BY-NC 4.0). 
long-standing problems in natural-language semantics and the philosophy of language.

Keywords: Arithmetic; cognition; knowledge; natural numbers; plural properties; plural quantification; propositional attitudes; propositions; representation; semantics.

All of us know a lot about propositions and numbers. We know that belief, assertion, and knowledge relate agents to what they believe, assert, or know-i.e. to propositions. Since what is believed or asserted can be true or false, we know that propositions are bearers of truth value, some are necessarily true, or false, while others are only contingently so. We also know they are asserted by uttering sentences. We know that natural numbers are the subject matter of arithmetic, which we learn as children. Our knowledge of propositions and numbers is commonplace. But it is also mysterious. We are philosophically in the dark about what they are. If asked Which entity is the number 3? or the proposition that the sun is a star? centuries of philosophical investigation haven't helped much. We ought to be able to do better.

I begin with a puzzlement our knowledge of numbers generates that isn't generated by our perceptual knowledge of trees. Aside from attempts to explain why there is no basis for radical skepticism about knowledge of the external world, philosophers haven't been overly perplexed by the fact that we know there are trees. But unlike trees, which we can see, philosophers generally agree that we can't see natural numbers. Although I know of one philosopher who has suggested that we can see certain sets, the members of which can be seen, I am not aware of any who have held that we can see numbers. ${ }^{1}$ Even if we can see some sets, the usual set-theoretic conceptions of natural numbers don't encourage the idea that we can perceive them.

\footnotetext{
1 After usefully reviewing the psychological literature on (physical) object perception, Maddy (1980) argues (i) that some perceptual beliefs, e.g. that there are 3 eggs left in the carton, are numerical in nature and (ii) that in her example the set containing the eggs is a constituent of the belief (which is judged to be 3-membered). Although I agree with (i), I will argue that our knowledge of natural numbers is better explained in another way.
} 
Frege's idea, that we can find out what numbers are by finding out what best explains our knowledge of them, is compelling. In sections 58 and 60 of The Foundations of Arithmetic, he says that nothing we can picture or imagine seems to be an apt candidate for being the number 4 . But he isn't deterred. Although we can, in his words, form no idea of the content of a number term, he insists that this no reason for denying that it has a content (see section 58 of Frege [1884] 1950). Rather than considering the term in isolation, we should, he thinks, ask what it contributes to meaningful sentences containing it. We must "Always [he says] keep before our eyes a complete proposition [sentence]. Only in a proposition [sentence] have the words really a meaning" (Frege [1884] 1950, section 60, p. 71). This is his "context principle," to which we can add the related principle: Natural numbers are whatever they have to be in order to explain our knowledge of them. There are many sentences containing numerical terms that express propositions we know. The strategy for finding out what natural numbers are is to investigate which assignments of meanings and referents to these terms best advance our ability to explain our knowledge of the truth of the propositions expressed by numerical sentences.

By 'our knowledge', I mean everyone's knowledge - children who know only a little, adults who know more, and number theorists who know much more. I presume this vast population shares a fair bit of common knowledge, even though some know more than others. Since no one knows all arithmetical truths - or even any collection from which all others could be validly derived - the set of arithmetical truths will outstrip all actual arithmetical knowledge. Still, we should be able to explain possible extensions of the knowledge we now have. I most want to know (i) how we achieve any knowledge of numbers at all, and (ii) how, with instruction, we can acquire more. In short, I am looking for a realistic starting point for a plausible account of our arithmetical knowledge.

One part of that starting point is what Frege called "Hume's Principle." It says that the number of X's is the same as the number of Y's iff the X's and Y's can be exhaustively paired off without remainder. E.g., the number of universities at which I have been a regular faculty member-Yale, Princeton, and USC - can be exhaustively paired off (without remainder) with the fingers I am now holding up. So, the number of universities at 
which I have served is the same the number as the number of fingers I am holding up. Both are three (in number). What is this property, being three (in number), predicated of? It's not predicated of any of my past faculty homes; neither Yale, Princeton, nor USC, is three (in number). It is not predicated of the set that contains just them; since the set is a single thing, it's not three either. Like the property being scattered, the property being three is plural. It is a property that applies, not to a single instance of any type of thing, but to multiple things of a given type considered together. My former $\mathrm{Ph} . \mathrm{D}$. students are scattered around the world, even though no one of them is scattered around the world, and the set containing them isn't scattered either.

With this in mind, consider the hypothesis that each natural number $\mathrm{N}$ greater than or equal to 2 is the plural property being $N$ (in number), and that the number 1 is a property applying to each individual thing considered on its own. ${ }^{2}$ Zero is a property that doesn't apply to anything, or things. Natural numbers are such cardinality properties. In the beginning, we gain knowledge of them by counting. Imagine a child inferring that I am holding up three fingers from her perceptual knowledge that $\mathrm{x}, \mathrm{y}$, and $\mathrm{z}$ are different fingers. Having learned to count-by memorizing a sequence of verbal numerals - she concludes that the fingers are three in number. She pairs off, without remainder, the fingers I am holding up with the words she speaks'one', 'two', and 'three' - thus ensuring that the fingers and the numerals "have the same number" in Frege's sense. The number they share is designated by the numeral, "three," that ends the count; it is the property being three which applies to these fingers.

This is the germ of an idea that combines the best of the Frege-Russell reductions with a striking, but incompletely developed insight in section 1 of Wittgenstein's Philosophical Investigations. The book begins with a quotation from Augustine.

When they (my elders) named some object, and accordingly moved toward something, I saw this and I grasped that the thing

2 This way of thinking of natural numbers grows out of two path-breaking works, one-(Boolos 1984) - by my former teacher, and the other-chapter 4 of (Gomez Torrente 2019) - by my former student. 
was called by the sound they uttered when they meant to point it out. Their intention was shown by their bodily movements, as it were the natural language of all peoples: the expression of the face, the play of the eyes, the movement of other parts of the body, and the tone of voice, which expresses our state of mind in seeking, having, rejecting, or avoiding something. Thus, as I heard the words repeatedly used in their proper places in various sentences, I gradually learnt to understand what objects they signified. (Wittgenstein 1958, section 1)

Wittgenstein uses the passage to illustrate a general conception of language he rejects - a conception in which naming is the essence of meaning. One reason he rejects this conception involves an imagined priority in introducing words into a language, and in learning a language. First comes our awareness of things in the world, then comes our use of words to talk about them. In learning the word, we first focus on candidates for its referent. Then we converge on the single candidate that best makes sense of the sentences they use containing the name.

Having sketched the general picture he wants to reject, Wittgenstein immediately jumps to a use of language which, he thinks, doesn't conform to it. He says

Now think of the following use of language: I send someone shopping. I give him a slip marked "five red apples." He takes the slip to the shopkeeper, who opens the drawer marked "apples"; then he looks up the word "red" in a table and finds the color sample opposite it; then he says the series of cardinal numbers - I assume that he knows them by heart - up to the word "five" and for each number he takes an apple of the same color as the sample out of the drawer. It is in this and similar ways that one operates with words [...] "But how does he know...what he is to do with the word 'five'?" [...] [W] hat is the meaning of the word "five"? — No such thing was in question here, only how the word "five" is used. (Wittgenstein 1958, section 1)

This emphasis on the use of the numeral 'five', rather than its referent, is illuminating. But the proper lesson isn't that its meaning is its use; the 
meaning of the word 'five', which is also its referent, is the property being five, which, being true of Wittgenstein's apples, isn't a use of anything. The lesson is that our use of the numeral in counting makes us aware of the property, which becomes cognitively associated with the numeral. First the use, leading to awareness of something to be named; not first the awareness of number, and then the decision to name it.

Counting, emphasized in the passage, establishes an epistemic foothold on a vast domain that none of us will ever actually count. Most of us know how to count to a trillion. But some of us don't know a verbal numeral for the number that comes after nine hundred ninety nine trillion, nine hundred and ninety nine billion, nine hundred and ninety nine million, nine hundred and ninety thousand, nine hundred and ninety nine. Still, most people have mastered the system of Arabic numerals, in which each natural number has a name, even though no one will ever use them all. These names are rigid designators the referents of which are fixed by descriptions that are implicitly mastered by those who understand them.

They can each be taken as designating a distinct cardinality property, as long as we don't run out of multiples to bear those properties. This might seem problematic, since it is likely that there are only finitely many electrons in the universe, and so only finitely many multiples of concrete things. But this needn't be problematic because we aren't restricted to counting concrete things. We can also count multiples which include plural properties among them, including numbers we have already encountered. This ensures that there is no end to larger and larger multiples, and so no end to our cardinality properties.

This picture gives us a way to explain our knowledge of numbers. Consider the child inferring from her perceptual knowledge that the number of fingers I am holding up is 3. At first, she does this by counting - saying the first three positive numerals - pairing them off with the fingers I am holding up. In time, counting won't always be necessary, because she will recognize at a glance when she is perceiving trios of familiar types. At that point she has the concept, being a trio of things (of some type), which is the plural property that is the number 3 . She learns a few other small numbers initially by counting, but eventually by perceptual recognition, and forming perceptual beliefs. She can perceptually recognize instances of these numbers, even 
though counting will remain her fallback when in doubt, or when the multiples increase in size. In this way, much of our knowledge of natural numbers is knowledge of plural properties grounded initially in perception, in cognitive recognition of things being of various types, and in cognitive action - counting the items falling under a given concept by reciting the relevant numerals while focusing one's attention on different individuals of the given type.

One doesn't first learn what numbers are, and then use them to count. One first learns to articulate numerals while pairing them with sequences of things. One begins to recognize and refer to numbers when one has mastered this practice and integrated it into one's cognitive life. In saying, "The number of blue books on the table is four, but the number of red ones is only three," one uses the numerals to attribute cardinality properties of multiples. The properties one attributes are numbers, which exist independently of us and of our language, but which we come to cognize only in virtue of the linguistic, and other symbolic, routines we have mastered.

Now for some refinements. I take the word 'three' to be analogous to the word 'blue'. Both can perform three grammatical functions: First, they can be used to designate properties of which other properties are predicated, as in and Blue is the color of a cloudless sky at noon and Three is the number of singers in the group. Second, they can be used to form predicates, as in The sky is blue and We are three, said by Peter, Paul, and Mary in answer to the question How many are you? Third, they can modify predicates, as in There is a blue shirt in the closet and There are three singers on stage. The numeral 'three' designates a plural property that applies to Peter, Paul, and Mary without applying to any one of them; the compound property being three singers on the stage applies to some individuals who are (collectively) three iff each is a singer on the stage. ${ }^{3}$

In a formal language, these distinct uses of the word 'three' might be regimented into uses of different words, but that needn't concern us here. The idea that properties, which we predicate not only of individuals but

3 To say that there are at least 3 singers on the stage is to say that some individuals who are three in number are each on the stage. To say that there are exactly 3 singers on the stage is to say that some individuals who are 3 in number are each singers on the stage, but no singers on the stage are collectively greater than 3 .

Organon F 27 (3) 2020: 282-301 
also of properties opens the door to paradox, unless restrictions are adopted. But the danger is general, and not, I think, specific to plural cardinality properties. There is, of course, no property that is true of any property $\mathrm{p}$ iff $\mathrm{p}$ isn't true of itself. But there is no need for one. I.e., there is no need for every meaningful predicate, including "is a property that is true of each property that is untrue of itself and of no others," to express a property. When it comes to the plural cardinality properties needed as natural numbers, no property, except the degenerate case of the number 1, is true of itself, because no natural number other than 1 is true of any single thing. There are, of course, plural cardinality properties that are true of some Fs of which they are not one as well, we may suppose, as plural cardinality properties that are true of some F's of which they are one. But this is also unparadoxical. Indeed, it would seem that all plural cardinality properties greater than or equal to 2 fall in both classes. Thus, it should be possible to explain our knowledge of arithmetic by taking natural numbers to be plural cardinality properties without paradox. Of course, no derivation, from logic itself, is contemplated.

What about a version of Frege's worry in section 46 of the Foundations of Arithmetic? While looking at Peter, Paul, and Mary standing on the stage next to The Beatles, I may say, equally, the number of singing groups on the stage is 2 or the number of singers on the stage is 7 . Indeed, I see 7 singers and I see 2 singing groups. I am not saying that any things I see are both 2 and 7 in number. One might think this if one thought that the 7 singers were identical with the two groups, but they aren't. Although the 7 singers constitute the 2 singing groups there is no genuine identity here. For one thing, the singers were all much older than the groups, while the groups weren't much older than the groups; indeed neither group was much older than the other. Whenever we count, the items counted must already be individuated. The number 3 is the plural property applying to all and only those individuals $\mathrm{x}, \mathrm{y}$, and $\mathrm{z}$ none of which is identical with any other. In saying this, we presuppose the individuation we need when stipulating that the values of the variables. Nothing more is needed to predicate the plural property. Given this, we can accommodate Frege's observation in section 46.

So far I have talked only about early stages of our knowledge of natural numbers, some of which is perceptual belief that qualifies as knowledge. If 
one's knowledge that $\mathrm{x}$ and $\mathrm{y}$ are fingers is perceptual, and one's knowledge that $\mathrm{x}$ isn't $\mathrm{y}$ is too, then one's knowledge that $\mathrm{x}$ and $\mathrm{y}$ are two things is also perceptual. If the fingers had been painted blue one could truly say, not only that one sees that those fingers are blue, but also that one sees that they are two in number. If two people are standing at a distance from someone holding up two blue fingers, one person, who has trouble making out what is displayed, might ask Do you see the color of those fingers? or Do you see the number of those fingers? The one with better vision might reply, Yes, I see their color; they are blue or Yes, I see the number of those fingers; they are two. So, there is a more or less ordinary sense of 'see' in which we can truly say that some color properties and some natural numbers, i.e. plural cardinality properties, can be seen. Don't wring your hands over this. If philosophy is worth doing, it should sometimes provide surprising, even shocking, knowledge. Here, it is knowledge about some of our knowledge of numbers.

Systematic arithmetical knowledge - e.g. of axioms and logical consequences of Peano Arithmetic - is more complicated. It isn't all logical knowledge of the sort Frege imagined. If natural numbers are cardinality properties, logic alone can't guarantee that there are any individuals, multiples, or distinct cardinality properties of multiples, let alone infinitely many. But we can use logic plus updated versions of Frege's definitions involving plural properties rather than sets to extend our knowledge of natural numbers. The definition of successor says that the plural property $N$ is the successor of the plural property $M$ iff some Fs, of which a given object $o$ is one, are $N$ in number, while the $F s$, excluding o, are $M$ in number. Given definitions of zero and successor we can define natural numbers as plural properties of which every property true of zero and of the successor of anything it is true of, is true. ${ }^{4}$

From this plus our initial perceptually-based knowledge, we can derive arithmetical truths. We can come to know that zero isn't the successor of anything by observing that if it were, some property true of nothing would be true of something. We learn that no natural number $M$ has two successors by observing that otherwise there would be plural properties N1 and $\mathrm{N} 2$ such that the N1s can't be exhaustively paired off with the N2s, even

4 See pp. 435-36 of Boolos (1984) for further discussion. 
though there are objects $\mathrm{O}_{\mathrm{N} 1}$ and $\mathrm{o}_{\mathrm{N} 2}$ such that the $N 1$ s excluding $o_{N 1}$ and the N2s excluding $o_{N 2}$ are both $\mathrm{M}$ in number, and so can be paired off. Knowledge of the companion axiom, that different natural numbers $N 1$ and N2 can't have the same successor, is explained in the same way. The axiom that every natural number has a successor is seen to be true when we realize that the plural cardinality properties we arrive at by counting can themselves be included in later multiples we count. This ensures we can always add one to any Fs of which a plural cardinality property M we have already reached is true. In this way, plural cardinality properties can help us explain not only our earliest knowledge of natural numbers, but also how systematic knowledge of elementary number theory can be acquired.

There are, of course, other ways of expanding the meager knowledge of arithmetic acquired in kindergarten. Most of us learned addition, subtraction, multiplication, and division without being exposed to Peano's axioms. The efficient, user-friendly routines we mastered are compatible with the perspective advocated here.

Is this perspective really correct? At least it is more promising than settheoretic accounts of natural numbers. Paul Benacerraf's original problem alerted us the fact that any reduction purporting to tell us what natural numbers really are - as opposed to what, for some purpose, it is convenient to take them to be - must provide a good reason for selecting one set theoretic-reduction from among the many different ways of identifying natural numbers with sets (Benacerraf 1965). Although each identifies individual numbers with sets that differ from those provided by other reductions, the different reductive systems do an equally good job of preserving all arithmetical truths. So, if that were the only criterion for justifying a reduction, we would have no reason for thinking that any of those reductions is uniquely correct. We might even have reason for doubting that any is correct. Surely, one may think, if the number three is identical with some set, there should be a reason it is one in particular, rather than any others. But, Benacerraf plausibly suggests, no set-theoretic reduction provides such a reason.

If one believes, as I do, that there really are natural numbers, which all of us know about, then we should look for the best explanation of our knowledge. I suspect that Benacerraf was right in suggesting that settheoretical reductions won't provide it. We do, of course, have knowledge 
of sets. But it doesn't, I think, come directly from anything as immediate as counting and perception. Rather, I suspect, it arises from activities in which teams, committees, and groups of coordinated individuals collectively succeed in doing things than no individual does - like winning a football game or carrying piano too heavy for any one of them. After we have admitted these, I suspect we come to recognize collections of things that are noticeably similar in some way, even though they may not do anything. Later, it occurs to us that we have no reason to exclude arbitrary collections of things. At this point the axioms of set theory can be considered and accepted.

Even then it is hard to take seriously the idea that natural numbers are sets - partly for Benacerraf's reasons, but also because by the time children and young adults have reached the level required to appreciate set-theoretic abstraction, the natural numbers have already been cemented in their minds as plural properties. It is tempting to put it this way: just as the color blue is naturally understood to be the property commonly possessed by this, that, and the other individual blue thing, so the number three is naturally understood as the property commonly possessed by this, that, and the other trio, each of which is three in number. But one must be careful. This way of expressing the idea can be misleading. It makes it sound as if pairs, trios, and multiples in general were a kind of thing. They aren't - at least in the sense that plural cardinality properties are true of pairs, trios, and multiples in general. When we say that Peter, Paul, and Mary are three, nothing of any kind is said to be three. Being three is a property that is never correctly predicated of anything. It is a property correctly predicated of some things - e.g. Peter, Paul, and Mary - without being predicated of them individually. Of course natural numbers are not all the numbers there are. What about all the others? Many at least seem to be constructions out of natural numbers. The questions, What sort of constructions? and How are they known? might be vitally important. But at least we have a start.

\section{Propositions}

I now turn to propositions, the dominant conception of which identifies them with sets of possible world-states at which sentences are true. What 
is it for a sentence $S$ to be true at w? Well, what is it for me to be a Slovak at $\mathrm{w}$ ? It is for $\mathrm{w}$ be a state, which, if the world were in it, I would be a Slovak. So, one might think, for $\mathrm{S}$ to be true at $\mathrm{w}$ is for $\mathrm{w}$ to be a state, which if the world were in it, $S$ would be true. But that won't do, because the truth value of S at world-states at which $S$ means nothing, or something other than what it actually means, is irrelevant to its actual truth conditions. What we ought to say when doing semantics is that for $\mathrm{S}$ to be true at $\mathrm{w}$ is for $\mathrm{w}$ to be a state which, if the world were in it, the proposition we actually use $S$ to express would be true. But saying that requires knowing about propositions, their relationship to sentences, and what it is for them to be true at world-states, before we give the truth-conditions of sentences at world-states.

One could simply stipulate that propositions are sets of world-states, and that for one to be true at $\mathrm{w}$ is for $\mathrm{w}$ to be a member of it. But that creates more problems than it solves. First, it entails that necessarily equivalent propositions are identical, which misrepresents propositional attitudes. Second, it denies the plausible idea that propositions have truth values because they represent things as being certain ways - e.g. red or roundand so are true when the things are red or round. By contrast, the question What does the set of worlds $w_{1} \ldots w_{n}$ represent? is nonsensical. It doesn't represent anything. Third, the identification of propositions with sets of world-states provides no explanation of what it is to entertain propositions, to believe them, or to describe others as believing them. Fourth, it inverts conceptual priorities. Instead of using propositions to define world-states, it treats world-states as unexplained primitives and uses them to define propositions. Finally, it misrepresents ordinary cognitions of all cognitive agents, no matter how primitive, as being about world-states, rather than about what we, and they, see, hear, taste, touch, and cognitively interact with in simple ways. Thus, what passes for knowledge of propositions, on the dominant conception, isn't knowledge. At best sets of world-states can, for some limited purposes, model propositions. But they aren't the real things.

Nor are what Frege and Russell called 'propositions' (see chapter 2 of Soames 2010). For Russell, propositions were mysteriously "unified" combinations of objects, properties, and propositional functions that are said to be true iff the properties are true of the relevant objects, or propositional 
functions. For Frege, they are mysteriously "unified" combinations of "complete" or "incomplete" senses said to be true iff the concepts presented by incomplete senses are true of (lower-level) incomplete senses, or (at the lowest level) of objects. Though each account suffers from its own difficulties, they share a crippling problem. No set, sequence, or formal structure, of, in Russell's case, objects and properties, or, in Frege's case, complete or incomplete senses, represents, on its own, anything as being any way. Not being representational, Frege-Russell propositions can't be the source of intentionality. Nor do they have truth conditions in virtue of any natural relation they bear to us. Theorists who use them treat them as models, which they interpret as being true in specified conditions. Unlike these models, of which ordinary agents know nothing, real propositions are the interpretations agents assign to utterances (Soames 2010, chapter 5).

This leads to a second defect. Traditional conceptions of propositions don't tell us what it is to entertain or believe them, or how agents acquire knowledge of them. This is crucial because propositions impose conditions on minds that entertain them that are more fine-grained than the truth conditions they impose on the world. To miss this is to miss their epistemic essence. Traditional conceptions of propositions also miss the semantic essence of sentences that express them. Just as proponents of traditional conceptions fail to explain what they call grasping a proposition amounts to, so they fail to explain what it means for sentences to semantically express propositions (Soames 2016).

Finally, no traditional conception of propositions fully accommodates their hyper-intensionality. While the deficiencies of the possible-worlds conception are legendary, the puzzles posed for Russellian and Fregean propositions by current analyses of names, natural kind terms, indexicals, and pronouns functioning as variables are well-known. Despite decades of effort, only limited progress has been made on the classic puzzles of Frege, Mates, Kripke, Perry, and Church (Frege [1893] 1952; Mates 1952; Kripke [1979] 1988; Perry 1977, [1979] 1988; Church [1954] 1988). Although linguistic science has made great progress in the last 70 years, the semantics and pragmatics of hyperintensional constructions aren't among its triumphs. They aren't because we lack a clear and widely accepted idea of what propositions are. Our empirical shortcomings with hyperintensionality are due to our 
metaphysical and epistemological cluelessness. To make empirical progress, we must attack foundational issues.

We start from the principle that agents are the source of intentionality. Agents represent things as being various ways when they perceive, visualize, imagine, or otherwise think of them as being those ways. Propositions are repeatable, purely representational cognitive act or operation types. When one perceives or thinks of $\mathrm{B}$ as hot, one predicates being hot of $\mathrm{B}$, thereby representing it as hot. The act represents $B$ as hot in a sense similar to the derivative senses in which acts can be irresponsible. Roughly, an act is irresponsible when to perform it is to neglect one's responsibilities. A similar derivative sense of representing allows us to assess cognitions. When to perceive or think of o as $\mathrm{P}$ is to represent o as it really is, we identify an entity, a particular cognition plus a property it has when it is accurate. The entity is a proposition, which is the repeatable mental act type of representing o as $\mathrm{P}$. The property is truth, which the act has iff to perform it is to represent o as o, in fact, is.

Entertaining, i.e. performing, is the attitude on which other attitudes are conceptually based. To judge that $\mathrm{B}$ is hot is to perform the predication in an affirmative manner, forming or strengthening one's disposition to act, cognitively and behaviorally, toward B in ways conditioned by one's experience with hot things. To believe that $\mathrm{B}$ is hot is to be disposed to judge it to be. To know that $\mathrm{B}$ is hot is for $\mathrm{B}$ to be hot, to believe that it is, and to be safe in so believing. Since believing a proposition p doesn't require cognizing $\mathrm{p}$, any organism that can perceive or think of the objects and properties in terms of which $p$ is defined can believe $p$-whether or not it can predicate properties of $\mathrm{p}$ or think about $\mathrm{p}$ at all. Knowing things about propositions involves distinguishing one's cognitive acts from one another. Self-conscious agents who can do this can ascribe attitudes to themselves and others, and predicate properties of propositions. Focusing on their own cognitions, they identify distinct propositions as different thoughts, which leads them to conceive of truth as a form of accuracy. How a proposition represents things is read off the acts with which it is identified, from which we derive its truth conditions. $\mathrm{P}$ is true at world-state $\mathrm{w}$ iff were $\mathrm{w}$ actual, things would be as p represents them - where what p represents is what any conceivable agent who entertains p would represent. Since this doesn't vary 
from world-state to world-state, p's truth conditions are essential to it. No one has to entertain $\mathrm{p}$ for $\mathrm{p}$ to be true (see chapter 2 of Soames 2015).

This view explains how an organism without the ability to think about propositions can know or believe them. It also explains how sophisticated agents acquire the concept proposition, and come to know things about them by monitoring their own cognitions. It even gives the beginning of an account of what it is for a proposition $\mathrm{p}$ to be the meaning of a sentence $\mathrm{S}$, as well as what it is for speakers to at least minimally understand $\mathrm{S}$. Roughly, it is for speakers to use $\mathrm{S}$ to perform p. Learning a language involves learning how to use its sentences to perform the same propositions that others do. One who is competent with the sentence 'Kripke is human' uses the name to refer to the man, the noun to refer to humanity, and the phrase 'is human' to predicate the property of the man - thereby performing the proposition that is the semantic content of the sentence. That's not the only proposition one thereby entertains. Using the sentence to predicate humanity of Kripke is itself a purely representational act, and so counts as a proposition $\mathrm{p}^{*}$. Since to perform $\mathrm{p}^{*}$ is to perform $\mathrm{p}$, but not conversely (just as to drive to work is to travel to work, but not conversely) the two propositions are cognitively distinct, despite representing the same thing in the same way.

The reality of representationally identical but cognitively distinct propositions resolves many worries about hyperintensionality (Soames 2015, 3945 and chapters 3-5). Consider uses of the 'Hesperus' and 'Phosphorus', which are unusual among names in imposing rich conditions on what it takes to understand them. Those who use them are expected to know that uses 'Hesperus' presuppose that it stands for something visible in the evening, while uses of 'Phosphorus' presuppose that it stands for something visible in the morning. To mix this up is to misunderstand them.

Suppose A utters "Hesperus is Phosphorus," addressing B, when both are presupposed to understand the names. A's utterance simultaneously asserts 2 representationally identical propositions, one which merely predicates identity of Venus and Venus, placing no restrictions on how the predication targets are cognized, the other which is entertained only by those who identify Venus using the two names. The former proposition, which is the semantic content of the sentence uttered, is necessary and knowable 
apriori. The latter proposition is necessary but knowable only aposteriori (since knowing it to be true requires knowing the names to be coreferential). Although both propositions represent Venus as being Venus (and only that) the hearer B can draw further conclusions from A's utterance. Knowing that A presupposes that both of them understand the names, B knows that A realizes he will be taken to be committed to the claim that the object Hesperus, visible in the evening sky, is identical with the object Phosphorus, visible in the morning sky. Since A anticipates this, B correctly concludes that A asserts the descriptively enriched proposition, along with the uninformative, bare proposition.

The fact that the descriptively enriched proposition is contingent doesn't prevent A from correctly saying "Necessarily Hesperus is Phosphorus." The proposition embedded under the modal operator isn't descriptively enriched, because taking the names to designate referents actually seen at certain times (which is what understanding the names insures) provides no information about when the referents are seen at possible world-states. This explains why uses of names often contribute descriptive assertive content to clauses under 'assert', 'believe' or other attitude verbs, without making such contributions under modal operators (Soames 2015, 84-88).

Next consider natural kind terms. 'Water' and 'heat' are directly referential designators of kinds - one involving hydrogen and oxygen, one involving the motion of molecules. In each case, a kind $\mathrm{K}$ is the semantic content that a term $\mathrm{G}$ contributes to propositions semantically expressed by sentences containing G. Given this plus the idea that the semantic content of $\mathrm{G}$ is G's meaning, one is tempted to think (i) that $\mathrm{K}$ is the meaning of G, (ii) that knowing this is knowing what $G$ means, and (iii) that since knowing what $G$ means is the same as understanding G, understanding G is knowing that it means K. This conclusion is false (Soames 2015, 88-89).

Understanding requires more than minimal competence with the term, which is simply the ability to use it with its semantic content. To understand a term is to have the knowledge and recognitional ability to use it to communicate in ways widely presupposed in the linguistic community. This dynamic, illustrated by 'Hesperus' and 'Phosphorus', but rarely found with ordinary names, is nearly always present with natural kind terms. Understanding them - in the sense needed to use them to communicate in ways 
widely presupposed by members of one's linguistic community - requires, in the case of 'water', knowing that users presuppose that it stands for something that can take the form of a colorless drinkable liquid that falls from the sky in rain and that is necessary for life. Similar observations apply to the terms 'heat', 'light', and 'red', the (full) understanding of which may sometimes require ability to recognize instances of the kinds.

Understanding in this sense is not a semantic notion in the sense of theories of semantic content. Our ordinary notions of understanding an expression $E$ and knowing what $E$ means track information commonly presupposed by most who use E. For a semantic theory that assigns a semantic content $\mathrm{K}$ to $\mathrm{E}$ to be correct, most minimally competent speakers must use $\mathrm{E}$ with that content, which must typically appear in the contents of speech acts performed using E. Widely shared presuppositions, which often carry extensive non-semantic content, distribute that content in the contents of speech acts involving the relevant expressions according to general pragmatic principles.

We can illustrate this with 'water' and ' $\mathrm{H}_{2} \mathrm{O}$ '. The proposition that water is water predicates identity of the kind water and itself, and so is knowable apriori. The proposition that water is the substance molecules of which are made up of one hydrogen atom and two oxygen atoms is both distinct from that proposition and non-trivial because it involves the content of a definite description. The proposition semantically expressed by the sentence 'Water is $\mathrm{H}_{2} \mathrm{O}$ ' depends on whether ' $\mathrm{H}_{2} \mathrm{O}$ ' is a name or an abbreviated definite description. Suppose it is a Millian name the understanding of which requires associating it with some conventional information. Suppose further that common users - most of whom aren't educated in chemistry - must, to be counted as understanding it, know that it is widely taken to stand for some kind of chemical compound involving hydrogen and oxygen. (Nothing more detailed than that.) Then, the sentence semantically expresses the same trivially true proposition that 'Water is water' does. But the linguistically enhanced proposition that arises from it by requiring the first argument of identity to be cognitively identified via the term 'water' and the second to be identified via the term ' $\mathrm{H}_{2} \mathrm{O}$ ' is knowable only aposteriori. Those who believe this proposition, understanding both 'water' and ' $\mathrm{H}_{2} \mathrm{O}$ ', realize that assertive utterances of 'Water is $\mathrm{H}_{2} \mathrm{O}$ ' will typically assert that 
the stuff, water, that comes in the form of a colorless, drinkable liquid that falls from the sky in rain is a chemical compound involving hydrogen and oxygen. Since speaker-hearers standardly presuppose that they understand the expressions, this informative proposition will normally be communicated and asserted, though, as we have seen, similarly rich descriptive enrichment will generally not occur under modal operators.

Here understanding the terms 'water' and ' $\mathrm{H}_{2} \mathrm{O}$ ' requires having different collateral information about what they stand for, despite the fact that their representational contents (which they contribute to the semantic contents of sentences containing them) are identical. A similar contrast can be drawn when understanding one term requires recognitional ability not required by understanding a second term with the same representational content. Let ' $\mathrm{R}$ ' be a Millian kind-term designating the same surface spectral reflectance property that the color term 'red' does. Suppose that fully understanding 'red' (in the sense of knowing what is typically presupposed when it is used) requires being able to visually identify red things, whereas no such ability is required to understand ' $R$ '. Then, the sentence, "the property being red is the property being $R$ " can be used in a context in which it is presupposed that the term 'red' is fully understood to assert a proposition which - when combined with propositions represented by one's visual experience - allows one to draw informative conclusions that couldn't be drawn from the proposition semantically expressed by the sentence, which is the uninformative proposition that the property being red is the property being red (Soames 2015, 92).

Finally consider the English attitude ascription Juan has just learned that water is $\mathrm{H}_{2} \mathrm{O}$ used to report a fact about a monolingual speaker of Spanish. Although the proposition semantically expressed by the ascription is, we many assume, false, the ascription can naturally be used to express a truth. This occurs when the semantic content of the ascription is enriched by requiring one who entertains the object of 'learn' to identify one argument of identity via the term 'water' or some translation of it, while identifying the other via ' $\mathrm{H}_{2} \mathrm{O}$ ', or some translation of it - where a term $\mathrm{T}_{2}$ is a translation of $\mathrm{T}_{1}$ only if conditions for understanding the two are roughly the same. Under these conditions, a use of the sentence Juan has just learned that that water is $\mathrm{H}_{2} \mathrm{O}$ asserts that he has only recently come to believe a certain informative proposition that makes no claims about words 
or translations. When, as is pretty standard, he is presupposed (i) to understand the relevant terms, and (ii) to take the descriptive information required by such understanding to be true of their referents, the assertive utterance will result in the assertion of a proposition that characterizes Juan as only recently coming to know that that a certain stuff that comes in the form of a colorless, drinkable liquid and falls from the sky in rain is a chemical compound involving hydrogen and oxygen.

This is just a sample of how getting the metaphysics of propositions right can help us make empirical progress in accounting for the semantics and pragmatics of hyperintensionality. Other examples include Kripke's Puzzle about Belief (Soames 2015, 81-84), puzzles about all manner of indexicals (Soames 2015, chapter 3, pp. 93-95, 112-16), and perceptual versions of Frege's puzzle (Soames 2015, 97-105).

\section{References}

Benacerraf, Paul. 1965. "What Numbers Could Not Be." The Philosophical Review 74 (1): 47-73. https://doi.org/10.2307/2183530

Boolos, George. 1984. "To Be Is to Be the Value of a Variable (of To Be Some

Values of Some Variables)." Journal of Philosophy 81 (8): 430-49.

https://doi.org/10.2307/2026308

Church, Alonzo. 1954. "Intensional Isomorphism and Identity of Belief." Philosophical Studies 5: 65-73. https://doi.org/10.1007/BF02221771. Reprinted in (Salmon and Soames 1988).

Church, Alonzo. 1988. "A Remark Concerning Quine's Paradox about Modality." In Propositions and Attitudes, edited by Nathan Salmon and Scott Soames. Oxford: Oxford University Press. Spanish version published in Analysis Filosofico 2, 1982.

Frege, Gottlob. [1884] 1950. The Foundations of Arithmetic. Trans. John L. Austin. Oxford: Blackwell.

Frege, Gottlob. [1893] 1952. "On Sense and Reference." In Translations from the Philosophical Writings of Gottlob Frege, 56-78. Trans. Peter Geach and Max Black. Oxford: Blackwell.

Gomez-Torrente, Mario. 2019. Roads to Reference: Oxford: Oxford University Press. https://doi.org/10.1093/oso/9780198846277.001.0001

Kripke, Saul. [1979] 1988. "A Puzzle About Belief." In Meaning and Use, edited by Avishai Margalit, 239-83. Dordrecht: D. Reidel. Reprinted in (Salmon and Soames 1988). 
Maddy, Penelope. 1980. "Perception and Mathematical Intuition." The Philosophical Review 89 (2): 163-96. https://doi.org/10.2307/2184647

Mates, Benson. 1952. "Synonymity." In Semantics and the Philosophy of Language, edited by Leonard Linsky, 111-36. Champaign Ill: University of Illinois Press.

Perry, John. 1977. "Frege on Demonstratives." The Philosophical Review 86 (4): 474-97. https://doi.org/10.2307/2184564

Perry, John. 1979. "The Problem of the Essential Indexical." Nô̂s 13 (1): 3-21. https://doi.org/10.2307/2214792. Reprinted in (Salmon and Soames 1988).

Salmon, Nathan and Scott Soames. Eds. 1988. Propositions and Attitudes. Oxford: Oxford University Press.

Soames, Scott. 2010. What is Meaning? Princeton and Oxford: Princeton University Press.

Soames, Scott. 2015. Rethinking Language, Mind, and Meaning. Princeton and Oxford: Princeton University Press.

Soames, Scott. 2016. "Yes, Explanation is All We Have." Philosophical Studies 173 (9): 2565-73. https://doi.org/10.1007/s11098-016-0636-0

Wittgenstein, Ludwig. 1958. Philosophical Investigations. Trans. G.E.M. Anscombe. $3^{\text {rd }}$ edition. New York: Macmillan. 